\title{
Seguridad, desconfianza y la dimensión simbólica de la segregación en urbanizaciones cerradas
}

Guénola Capron. Universidad Autónoma Metropolitana Azcapotzalco, Ciudad de México, México.

RESUMEN | El artículo busca analizar la dimensión simbólica de la segregación residencial dentro de las urbanizaciones cerradas. A partir de un enfoque espacial micro, examina la idea de la integración social y funcional entre conjuntos cerrados y barrios pobres. Basado en entrevistas a residentes y empleados, propone estudiar las prácticas, sus significados y las representaciones de residentes y empleadas domésticas de urbanizaciones cerradas de la Zona Metropolitana del Valle de México. Si bien las prácticas de separación física y distanciación simbólica dentro de la casa reflejan una discriminación y una desconfianza histórica de las clases acomodadas hacia los pobres, los dispositivos sociales y espaciales de segurización y segregación que operan como clasificadores de los individuos en función de su grado de confiabilidad y peligrosidad, instauran un orden, nuevo, de una institución de vigilancia privada. La cercanía física entre grupos genera una segregación simbólica, efecto perverso de la segregación económica y política.

PALABRAS CLAVE | segregación, barrios cerrados, seguridad ciudadana.

ABSTRACT | This article seeks to analyze the symbolic dimension of residential segregation within gated communities. It discusses the idea of social and functional integration between gated communities and popular neighborhoods from a micro spatial approach. Based on interviews with residents and employees, it aims to study the practices, their meanings and the representations of residents and domestic workers of gated communities in the Metropolitan Area of the Valley of Mexico. While the practices of physical separation and symbolic distancing within the home reflect discrimination and a historical distrust of the well-off classes towards the poor, the social and spatial safety, and segregation devices that operate as classifiers of individuals based on its degree of reliability and danger, establishes a new order of a private surveillance institution. The physical closeness between groups generates a symbolic segregation, a perverse effect of economic and political segregation.

KEYWORDS | segregation, gated communities, citizen security. 


\section{Introducción}

Las urbanizaciones cerradas de clases media-alta y alta se han convertido en el principal símbolo de la ciudad neoliberal, desigual y erizada de dispositivos de seguridad. Constituyen una especie de laboratorio experimental para estudiar la vida social en los ámbitos residenciales de este rostro de la ciudad neoliberal. Los motivos para vivir en una urbanización cerrada son la valorización de la propiedad inmobiliaria, la búsqueda de la tranquilidad residencial y del entre-sí (Donzelot, 1999), la distinción y la seguridad. En América Latina, en particular en México, el sentimiento de inseguridad y el miedo son motivos predominantes (Caldeira, 2000), que colorean la experiencia urbana de los residentes. Si bien el funcionamiento de los mercados de suelo es, tal cual lo sostienen Sabatini y Brain (2008, p. 23), "la clave de la segregación residencial” en las ciudades latinoamericanas, el temor al otro y la inseguridad explican las lógicas de los actores individuales. Permiten comprender el efecto que tienen los mecanismos de segregación como ejercicio de un poder de los pudientes sobre los pobres, promovido por agentes públicos o privados.

Entender la dimensión simbólica de la segregación (Saraví, 2008) ayuda a explicar por qué, desde la división colonial entre la ciudad de los indios y la ciudad de los españoles, han perdurado en el tiempo patrones de segregación residencial que buscan apartar los residentes dominados o pobres de los habitantes acomodados. Desde finales de los años setenta, después de la ciudad industrial, han emergido nuevos patrones de la división social del espacio, como las urbanizaciones cerradas. En el presente artículo, me pregunto de qué manera, dentro de estos conjuntos residenciales cerrados, las clases media-alta y alta logran mantener a distancia a otros grupos cuya proximidad espacial es necesaria, pero indeseada. Tal es la respuesta al hecho de que todos los días entra gente foránea a los conjuntos residenciales, entre ellos los numerosos trabajadores que necesitan las urbanizaciones cerradas para funcionar adecuadamente: empleadas domésticas, jardineros, trabajadores de la construcción, agentes de seguridad y policías.

Esta investigación está respaldada por una etnografía con base en visitas, 30 entrevistas en profundidad a residentes y 18 a trabajadores, realizadas entre 2008 y 2018. En este periodo se incrementó la violencia en México a raíz de la "guerra contra el narco" llevada a cabo por el presidente Felipe Calderón y se desató una lucha feroz entre los cárteles de la droga, acompañada de una ola de crímenes de alto impacto y desapariciones, lo que fomentó un incremento del temor ciudadano. Las entrevistas fueron realizadas en tres fases en los tres principales sectores urbanos que concentran conjuntos cerrados de clases media-alta y alta en la Zona Metropolitana del Valle de México (Santa Fe, Interlomas, Zona Esmeralda). Además de urbanizaciones cerradas - productos inmobiliarios creados ex nibilo-, estos sectores urbanos, extensos, tienen centros comerciales y, para el caso de Santa Fe, torres de oficinas inteligentes. En comparación con los pequeños condominios cerrados de decenas de casas incrustados en colonias de clase media y hasta colonias populares, las urbanizaciones cerradas, horizontales o verticales (torres de viviendas), de cierto tamaño, ofrecen amenidades como equipos deportivos, salones de eventos y casas club que promueven la sociabilidad interna. Las entrevistas, aunque con 
enfoques ligeramente distintos en las tres fases de trabajo de campo, se centraron en las prácticas de segurización de los habitantes, los significados del miedo y las representaciones sociales mutuas de residentes y empleados.

En una primera parte, discutiré la importancia de considerar la dimensión simbólica de la segregación, en particular para el caso de las urbanizaciones cerradas, poniendo énfasis en la desconfianza como operador social de la segregación. En la segunda, analizaré el tipo de relación social que se establece entre residentes y foráneos dentro de la urbanización cerrada y mostraré la continuidad de los esquemas mentales. En la tercera, describiré cómo la urbanización cerrada, por medio de dispositivos de vigilancia, opera la separación con base en la desconfianza.

\section{La dimensión simbólica de la segregación}

La segregación, en la perspectiva del análisis de la distribución espacial de la población en el espacio, es definida como la concentración de grupos sociales homogéneos, sea por factores socioeconómicos, etarios, étnicos o religiosos, así como por su grado de proximidad espacial (Sabatini, Cáceres \& Cerda, 2001). La concentración y la homogeneidad social son, según Sabatini (2003), dos de las tres principales dimensiones objetivas de la segregación residencial. Son las más estudiadas, en particular desde los trabajos de Massey y Denton (1988). La tercera dimensión, subjetiva, es el prestigio o desprestigio social de las áreas residenciales, es decir, las "imágenes, percepciones, reputación y estigmas territoriales asignados por la población de la ciudad a algunos de sus vecindarios" (Sabatini, 2003, p. 7). Sin embargo, el autor no ahonda mucho en ello, dándoles más importancia a las dos primeras dimensiones, ya que privilegia la explicación y comprensión de los mecanismos institucionales de la segregación.

Otra definición de la segregación es aquella propuesta por Grafmeyer (1994), quien identifica tres dimensiones: la distribución desigual de los grupos en el espacio, el acceso desigual a los equipamientos y servicios, y la espacialización de la distancia social entre los grupos. Al contrario de Sabatini y sus colegas, hace más hincapié en la tercera, en la voluntad de apartar y separar a un grupo del resto de la sociedad, sea físicamente (el apartheid) o simbólicamente. En efecto, los esquemas mentales y morales, es decir, la estigmatización de territorios enteros, desempeñan un papel importante en la distanciación social y evitación de áreas de la ciudad y en su desconocimiento, provocando un círculo vicioso: se evitan porque son estigmatizadas, pero mientras más se evitan, menos se conocen, más son estigmatizadas, transformándose eventualmente en guetos. Aquí no ahondaré en ello, ya que lo que me interesa es la escala de la urbanización cerrada. Grafmeyer (1994) pone el énfasis en el estudio de conflictos y ajustes sociales y del contraste entre las prácticas y usos de la ciudad, y las construcciones vividas y esquemas cognitivos de la ciudad, lo que más me interesa aquí.

Si bien a nivel estadístico, al menos para el caso de Bogotá, hubo un aumento de la microsegregación para los hogares de niveles más altos entre 1973 y 1993 y una disminución entre 1993 y 2005 (Aliaga Linares \& Álvarez Rivadulla, 2010; Dureau, Lulle, Souchaud \& Contreras, 2015), en las dos últimas décadas tanto el 
fenómeno de la gentrificación en los centros urbanos, como el desarrollo de urbanizaciones cerradas en las periferias pobres de las ciudades, han producido una reducción de la distancia física entre poblaciones y barrios situados en polos extremos de la escala social. No significa mecánicamente una reducción de la segregación social. Por la misma cercanía física se producen tácticas de distanciación social en el espacio ya sea en una calle o entre dos barrios vecinos. En efecto, la coexistencia entre grupos sociales diferentes no está exenta de conflictos, como lo muestra, entre otros, el caso de la calle Regina al sur del centro histórico de la Ciudad de México, donde conviven de manera conflictiva antiguos pobladores de origen popular y jóvenes artistas y creativos atraídos por el ambiente y los buenos precios inmobiliarios (Díaz, 2019). Décadas atrás, Chamboredon y Lemaire (1970) ya habían mostrado que la cohabitación entre clases medias y clases populares en los grandes conjuntos de vivienda de interés social franceses estaba lejos de la imagen armoniosa que promovía el Estado, cercano a lo que Sabatini (2003) califica de "adolescencia urbana”, es decir, la dificultad en soportar la diferencia social en los mismos espacios o en territorios cercanos.

Sin embargo, para el caso de las urbanizaciones cerradas de Santiago de Chile, Sabatini y Salcedo (2007) mostraron que la reducción de la escala métrica de segregación tiene externalidades positivas. Estas son funcionales, debido a la provisión de servicios y el empleo que ofrecen las urbanizaciones cerradas; y simbólicas, por el cambio de imagen que provoca la llegada de urbanizaciones de alto nivel a espacios que anteriormente estaban estigmatizados. Los autores enfatizan que esta integración muestra que las clases media-alta y alta no son totalmente renuentes a vivir cerca de los pobres. Ello tiene aspectos positivos y negativos, dependiendo de los contextos locales. Pero agregan que esta integración funcional y simbólica ocurre "si, al menos, los residentes pobres y ricos no se temen entre sî" (Sabatini \& Salcedo, 2007, p. 601). Lo que planteo es que, en contextos altamente inseguros como es el caso de México, y quizá de toda América Latina, el factor “inseguridad” desempeña un papel importante en los procesos de desconfianza y estigmatización de poblaciones y territorios. Además, con base en un trabajo empírico apoyado en entrevistas a pobladores de un barrio pobre y condominios cerrados de clase media colindantes, Ruiz-Tagle (2016) evidenció que las ventajas laborales y funcionales de la llegada de nuevas poblaciones de clase media a zonas con un perfil socioeconómico más bajo deben ser matizadas y que no existen vínculos sociales entre las comunidades. RuizTagle y López (2014) sostienen que Sabatini y sus colaboradores ponen demasiado énfasis en la dimensión espacial de la segregación y no en la segregación social, en la cual la parte simbólica tiene un papel activo.

Si bien las urbanizaciones cerradas han sido consideradas por muchos como una muestra del aumento de la segregación en ciudades en tiempos del capitalismo global (Capron \& Esquivel, 2016; Pérez, 2011; Roitman, 2003), Sabatini y Brain (2008) argumentan que los muros son más bien una condición de posibilidad para que clases medias-altas y altas se instalen en medio de colonias populares o junto a ellas. No obstante, el muro como elemento de separación, barrera o frontera, tiene una carga simbólica que se puede interpretar desde la semiótica de la arquitectura o del espacio, siempre relacionándolo con las representaciones sociales y prácticas de 
los sujetos, aunque no de manera determinista y mecánica (Lacarrieu \& Thuillier, 2004). El muro como elemento simbólicamente separador ha sido ya objeto de múltiples trabajos, empezando por Cidade dos muros, de Teresa Caldeira (2000), por lo que no insistiré en ello. Recordaré brevemente que, en el caso de las urbanizaciones cerradas, el muro significa una voluntad, no individual, más bien colectiva, de distanciamiento social. El muro no es la única forma de separar. En el fraccionamiento de Condado de Sayavedra en el municipio de Atizapan de Zaragoza (Zona Metropolitana del Valle de México), el valle de un riachuelo y los espacios verdes que delimitan el fraccionamiento cerrado conforman un cinturón que constituye una segunda barrera, natural, contra la "amenaza" de las colonias populares vecinas. Cuando se quisieron instalar "paracaidistas", ${ }^{1}$ los vecinos de Condado Sayavedra hicieron todo para desalojarlos.

Esto me lleva también a replantear de otra manera la tesis del reflejo entre desigualdades sociales y segregación residencial que cuestiona Sabatini en varios trabajos criticados por Ruiz-Tagle y López (2014). Si bien en efecto no siempre hay una coincidencia entre el aumento de desigualdades y el incremento de la segregación residencial (es la tesis de Sabatini y sus colegas), el encerramiento debido al alza del crimen instala una "cultura del miedo" que mezcla un fenómeno objetivo, la victimización, con otro subjetivo, la desconfianza hacia las clases peligrosas (es la tesis de Ruiz-Tagle y López). La percepción de inseguridad que va más allá del solo miedo al delito refleja la situación de incertidumbre en la cual se encuentran envueltos los sujetos en la "modernidad líquida" (Bauman, 2007). Esconde un "miedo al otro" tenaz, cualquiera sea la condición social y cultural del que teme y de aquel a quien se teme. Por ejemplo, son los negros y los latinos, sobre todo los mexicanos, en las gated communities de Estados Unidos (Davis, 1990, 2003; Low, 2003). En el caso de las urbanizaciones cerradas de Monterrey en México, son las empleadas domésticas indígenas, jóvenes, recién llegadas de su lugar de origen, el clasismo social doblándose de un racismo anclado en las mentalidades de las clases media y alta (Durin, 2013). Incluso en los barrios pobres, entre otros conjuntos de vivienda de interés social, el "otro desconocido tiene cara de delincuente", reflejando la desconfianza social entre vecinos (Lunecke, 2016).

La seguridad es un sentimiento psicosocial sustentado en la confianza, un cemento social fuerte, condición de la existencia de la cooperación y de relaciones económicas y políticas, frente a los intereses individuales, como lo han mostrado numerosos estudiosos desde Durkheim, Weber y, sobre todo, Simmel. Kessler (2008) plantea que el contexto latinoamericano actual de alta inseguridad e incertidumbre es también uno de "erosión generalizada de la confianza, incluso en los lazos cotidianos" (p. 153). La desconfianza generada por la crisis de inseguridad incrementa las desigualdades simbólicas y eleva lo que Saraví (2008) califica de "espesas murallas simbólicas", creando estrategias de la gente para distanciarse, de una manera u otra, de las clases percibidas como inferiores y "peligrosas". Estas fronteras simbólicas son, según Lamont y Molnár (2002), "distinciones conceptuales realizadas por actores sociales para categorizar objetos, personas, prácticas, 
incluso tiempo y espacio" (p. 168). Las distinguen de las fronteras sociales que construyen diferencias de clases. En el caso que me interesa, las fronteras simbólicas se elevan entre las urbanizaciones cerradas, todas verdes y bonitas en las representaciones sociales de las amas de casa, y las colonias de los trabajadores pobres que las patronas perciben como peligrosas, feas y sucias, aunque nunca lo hayan sido. La desconfianza y el temor, las representaciones del otro, cuestionan las posibilidades de integración social entre barrios pobres y urbanizaciones cerradas, como lo han destacado Pérez (2011) y Ruiz-Tagle (2016), que adhieren a la idea de Saraví (2008). Según este, simbólicamente pero también funcionalmente, estos mundos están "aislados": la proximidad espacial no genera proximidad social. Se trata de un proceso de construcción y resignificación lábil de las fronteras sociales y simbólicas, el cual también ha sido mostrado por Moctezuma (2017) en relación con los grandes conjuntos periféricos de vivienda de interés social, con casas construidas por empresas privadas, donde residen trabajadores pobres, pero al menos con salarios del sector formal. Estos grupos tienen estrategias de distinción frente a las colonias populares autoconstruidas vecinas, donde los mercados de la vivienda y del empleo tienden a ser mucho más informales, pero el nivel socioeconómico de la población no está tan alejado. Las fronteras simbólicas son producto del temor al otro delincuente (Lunecke, 2016). En el caso de las urbanizaciones cerradas, existe una relación marcada entre - por un lado- las desigualdades simbólicas expresadas en las representaciones y prácticas sociales de la vida cotidiana; y -por el otro- la segregación socioespacial; es decir, la operación del distanciamiento social y espacial en relación al grupo social estigmatizado. Las prácticas y representaciones del otro son atravesadas por el temor y la desconfianza vinculados a la situación de inseguridad.

En este sentido, la dimensión simbólica de la segregación actuaría como un factor "maligno" de ella. Es lo que quisiera tratar de comprobar con base en un caso empírico tomado en México, estudiando no solo la relación entre asentamientos vecinos, como lo hacen Pérez (2011) y Ruiz-Tagle (2016), sino lo que ocurre en la cercanía física, dentro de la urbanización cerrada y en el interior de la casa. Un estudio similar, dentro de la casa y del "barrio", ha sido realizado por Garrido (2013) en la ciudad filipina de Manila. Se apoya en la idea de la construcción de sentidos de lugares distintos, que permite mantener la distancia simbólica entre dominantes (los colonos de una urbanización cerrada) y dominados (un asentamiento popular vecino) y la relación de poder de los unos sobre los otros. La propuesta de Rodríguez (2014), aunque con lineamientos teóricos diferentes a los míos (desde la teoría de la renta de suelo y no de las interacciones), busca redefinir la segregación a partir de una perspectiva de poder y no solo de manera descriptiva, como lo hace gran parte de la literatura sobre segregación que se apoya en los trabajos de la Escuela de Chicago, y esta propuesta me parece fructífera. En el presente trabajo, ahondaré en la relación de poder entre patrones y empleados subyacente a las prácticas de segregación. Me interesaré específicamente en los dispositivos que permiten segurizar el conjunto residencial y distanciar, tanto social como simbólicamente, a los sujetos que el sistema de la urbanización cerrada considera como potencialmente peligrosos, amenazantes y desconfiables. Los trabajos de Pérez, Ruiz-Tagle, Garrido, así como el de Swyngedouw (2013) acerca de las prácticas e interacciones de distanciación en 
el metro de Chicago, abren la vía a un estudio de la segregación en niveles micro en espacios residenciales o espacios públicos, a partir de la observación y comprensión de los comportamientos y las prácticas sociales.

\section{El enemigo interior}

En México, como en otros países de América Latina, el "sospechosismo" hacia los pobres, la estigmatización y criminalización de la pobreza no son fenómenos nuevos. Como lo muestra Pablo Piccato en Ciudad de sospechosos (2010), la desconfianza es una construcción histórica y social y lo ha sido desde el porfiriato, producto de la dominación de las elites sobre los pobres y de la relación de poder asimétrica entre las dos clases. La delincuencia es un constructo social. "Los delitos contra la propiedad eran tanto un producto de las condiciones económicas como el resultado de actitudes culturales hacia las diferencias de clase y la criminalidad" (Piccato, 2010, p. 204) que criminalizaban la pobreza. La desconfianza, de la elite hacia los pobres y viceversa, de los pobres hacia la autoridad, permeaba las relaciones interpersonales, en particular entre los "amos" y las empleadas domésticas.

Por un lado, existía una desconfianza de los pobres hacia la elite por las injusticias e impunidad emergentes. Varios ejemplos se pueden dar de estas injusticias: un delito que se producía en una zona adinerada podía no ser castigado, mientras el consumo de alcohol empezaba a ser fuertemente reprimido. Los pequeños "préstamos" de herramientas de materia prima del lugar de trabajo, que hasta la segunda mitad del siglo xix habían sido tolerados como complemento del salario bajo de los trabajadores, empezaron a ser criminalizados por el Código Penal, lo que era considerado como una injusticia por los trabajadores. Existía desconfianza hacia los jueces y, a partir de los años 1920, hacia los gendarmes, quienes, alejándose de la vida vecinal, comenzaron a trabajar de la mano con políticos corruptos y grandes "rateros modernos", profesionistas, cuyo delito excedía de lejos el pequeño hurto cotidiano, severamente castigado, de quienes robaban para poder sobrevivir.

Pero, sobre todo, había una fuerte desconfianza de la elite hacia los pobres, en particular en las relaciones laborales. La sospecha se extendía a todos los pobres, fueran culpables o inocentes, sin presunción de su inocencia. Como señala Piccato (2010), en los inicios del siglo xx se empezó a construir la representación de los pobres "como una clase de ladrones potenciales" (p. 243). El personal, en particular las empleadas domésticas que se alojaban en el mismo domicilio de sus amos en ausencia de relaciones contractuales de trabajo, "vivía bajo permanente sospecha, de manera individual o como grupo" (p. 236). A las sirvientas se les pedía cartas de recomendación o, en caso de no tenerla, una recomendación oral de otra empleada, práctica que se ha mantenido a través de las décadas. "La desconfianza era, de acuerdo con los observadores, la nota dominante en las relaciones laborales" (p. 238). Otros sospechosos designados como "rateros" a finales de siglo xix eran las personas que tenían una ocupación laboral visible, en contacto con la vida pública de la calle, como los artesanos, los zapateros y los albańiles.

Las representaciones sociales clasistas han perdurado en el tiempo. Hoy en día, en las urbanizaciones cerradas, en caso de robos a una casa-habitación se sospecha poco 
de los vecinos u otros residentes. Los que cristalizan los miedos y las ansiedades de muchos de los habitantes que viven en fraccionamientos y conjuntos cerrados son los albañiles, las trabajadoras del hogar y hasta los policías. "Se sabe que los trabajadores son todos un poco rateros", dice un residente. Incluso, los policías que conocen las rutinas internas de la urbanización siguen construyendo una figura ambigua, a la vez próxima (el "poli") y sospechosa (el "ratero"). No obstante, en las urbanizaciones cerradas, la figura cariñosa del "poli” tiende a desaparecer por la profesionalización del servicio y la rotación del personal de seguridad. El policía, empleado modelo, puede cambiarse en el policía ladrón, ya que, finalmente, también es pobre (un agente de seguridad privada gana alrededor de tres salarios mínimos mensuales).

Las principales sospechosas son las empleadas domésticas. Varias patronas entrevistadas cuentan hurtos en sus casas, que atribuyen a sus trabajadoras, con o sin pruebas. Bertha, una residente de Bosques de Santa Fe, recuerda que tuvo que despedir por "abuso de confianza" a una empleada que, según ella, le robaba ropa, botellas de vino, "nada grave", robos hormiga similares a los pequeńos hurtos en el lugar de trabajo justificados por los salarios insuficientes que señalaba Piccato para el siglo xix. Si bien existen casos comprobados de empleadas que han robado a sus patronas, también existen casos contrarios de empleadas sospechadas que no eran culpables. Una entrevistada, Laura (Chiluca, Zona Esmeralda), relata que un residente fue a solicitar las grabaciones a Seguridad porque tenía la certeza de que su empleada lo había robado, y resultó ser una equivocación.

Pero no todos los empleadores desconfían de sus empleados. La confianza es el pilar de la relación laboral entre ellos, en particular para las empleadas domésticas, quienes pueden esperar tener un buen trato y salario si son leales, honestas, discretas; en fin, confiables (Toledo, 2013; Vidal, 2007). Muchas de las empleadoras entrevistadas tienen confianza en sus empleadas y trabajan con ellas desde hace ańos, incluso antes de que se vinieran a vivir a una urbanización cerrada. Probablemente, como lo señala Garrido (2013) acerca de las urbanizaciones cerradas de Manila, las tratan bien y como a iguales. La relación puede haber sido construida a lo largo de los años. Puede incluir el hacer regalos de alimentos, ropa u otros objetos usados, pero siguiendo la lógica de un don asimétrico, porque hay una relación de poder entre las dos partes, dependiente de la diferencia de recursos socioeconómicos entre las personas, así como de la necesidad del que recibe y su libertad de aceptar o rechazar el "regalo" (Galeano Gasca, 2018, citando a Golderner). No obstante, la confianza que se le otorga a la empleada es limitada en el espacio (la casa) y el tiempo (entre semana cuando la empleada es de tiempo completo, o de día cuando es de entrada por salida) y atribuida por una actividad determinada: el hacer el aseo o ser nana de los hijos dentro de la urbanización cerrada.

Algunas amas de casa dicen confiar en su trabajadora, pero imaginan nuevos riesgos, temen las relaciones amorosas o sociales que pudiera tener la empleada y que podrían colocar a la familia en una situación de vulnerabilidad a través del novio o de los conocidos de la trabajadora, haciendo eco de lo que describe Durin (2013) para el caso de San Pedro Garza García en Monterrey, uno de los municipios más ricos del país. Por ejemplo, una empleada que se había enamorado de un albañil que laboraba en la casa en construcción de enfrente generaba mucho temor en su 
patrona. Incluso, una situación como esa puede ser motivo de despido. Las cámaras de vigilancia colocadas dentro de la casa, sobre todo cuando las trabajadoras cuidan a los hijos, a veces sirven para vigilar cada uno de sus gestos (Durin, 2013). En el contexto de una crisis de inseguridad aguda en Monterrey, el alcalde del municipio de San Pedro Garza García propuso en 2011, aunque con poco éxito, un programa "De ti y por ti" para empadronar a todos los trabajadores, incluyendo a las empleadas domésticas de planta. A cambio de una credencial para acceder a los servicios municipales, solicitaban datos sobre su lugar de origen, sus familiares, etcétera, con el fin de controlarlos, agregando que "el $60 \%$ de los robos a casahabitación los cometen trabajadores domésticos” (Durin, 2013).

La desconfianza, cuando existe, se expresa hasta en el interior de las casas, en el maltrato, por palabras despectivas, humillantes y prejuiciosas, a veces cargadas de racismo hacia los indígenas, o pequeños gestos vejatorios que marcan la distancia social y la inferioridad, como lo destacan también Durin (2013) y Toledo (2013) acerca de las empleadas domésticas en Monterrey y en Tlaxcala, sobre todo cuando son de tez morena. Por ejemplo, una empleada entrevistada cuenta que los niños de la casa le decían "eres una gata". Además, las empleadas en muchos casos han internalizado los comportamientos de servidumbre e inferioridad (Capron, 2019a; Durin, 2013), producto de siglos de dominación: ellas se apartan sin que sea necesario que se lo digan (lo hace "porque ella lo quiere", dice una entrevistada). El llevar un uniforme, si bien a menudo se explica por razones de limpieza (no ensuciar la ropa), también es una manera de identificar al personal doméstico en su condición de diferente y hasta inferior, y disciplinar los cuerpos. Por ejemplo, en un condominio cerrado del área metropolitana de Santiago de Chile, las empleadas tienen la obligación de usar uniforme dentro del conjunto (Pérez, 2013, p. 207).

$\mathrm{La}$ arquitectura de las casas modernas, dentro de las urbanizaciones cerradas y fuera de ellas, está divida entre los espacios de producción (cocina, espacios para planchar, etc.) y los espacios dedicados a la vida de la familia. Las empleadas suelen quedarse en los espacios reservados a la reproducción social, principalmente la cocina. Los cuartos del personal doméstico de tiempo completo, minúsculos, están alejados de los espacios del resto de la familia. Las trabajadoras del hogar muy a menudo tienen sus propios baños, incluso si son de entrada por salida. La organización del espacio doméstico, jerarquizado, consolida las desigualdades sociales, expresando un control sobre las empleadas (Pérez, 2013). Ellas raras veces se sientan con los miembros del hogar para comer. Una joven cuenta que la empleada de la casa come con sus propios cubiertos. Mónica Toledo (2013) relata el caso de una trabajadora del hogar que no quiere comer sentada con sus patrones porque no sabe manejar bien los cubiertos, además de que se siente mal en estas situaciones (p. 58). Si bien las empleadas pueden ser "casi" de la familia y las patronas y las trabajadoras pueden tener cierta cercanía y momentos de intimidad, aunque muchas veces en un solo sentido (la patrona habla de sí misma, pero la trabajadora del hogar no trae sus problemas a la casa de su empleadora), saben ubicarse cuando vienen invitados; no son "confianzudas", "igualadas", como lo destaca Toledo (2013, p. 58), y en estos momentos se vuelven discretas y casi invisibles. Aun si las empleadas son de entrada por salida, no siempre las amas de familia les dejan las llaves de la casa. Una joven residente dice que el lugar 
de la empleada es el baño. En muchos casos es latente un miedo a la contaminación de los pobres asociados con la suciedad, lo que justifica mantener a las trabajadoras lo más alejadas posible y también expresa un temor a la subversión del orden social, en el sentido que le da Mary Douglas (1973). La misma joven destaca que no le gustaría encontrar a la empleada buscando en sus cosas. De hecho, Garrido (2013, p. 1351), señalando hechos de las urbanizaciones cerradas de Manila muy similares a lo que ocurre en México, menciona que, cuando las empleadas domésticas limpian los cuartos de la familia, tienen que mantener la puerta abierta.

\section{Los dispositivos de segurización y segregación}

La desconfianza de las clases superiores hacia las clases inferiores se inscribe dentro de una larga historia: vimos que caracteriza los comportamientos de la elite al menos desde finales del siglo XIx. Tampoco es exclusiva de las urbanizaciones cerradas, pues ocurre lo mismo en los barrios acomodados de la ciudad abierta. Y tampoco es forzosamente la actitud que tienen todas las patronas, no siempre clasistas, hacia las trabajadoras del hogar. Como lo plantean Sabatini, Rasse, Mora y Brain (2012) siguiendo a Gramsci, la cultura está formada por capas sedimentadas de significados que abren la posibilidad de la libertad frente al orden jerárquico y paternalista de las clases altas, incluso dentro de este mismo grupo. Pero lo nuevo y lo diferente en comparación con la ciudad abierta es que los dispositivos y las técnicas de control y reducción de la incertidumbre, propios de la "modernidad líquida" (Bauman, 2007), de la ciudad neoliberal, establecen la sospecha como un mecanismo institucional y respaldan y hasta fomentan la desconfianza hacia los "otros", en particular hacia los trabajadores. Lo que intriga es que personas que no necesariamente son clasistas, acepten vivir en espacios residenciales que erigen la sospecha en sistema.

La urbanización cerrada es un espacio altamente controlado por dispositivos materiales, tecnológicos y sociales de vigilancia. Estos dispositivos buscan construir homogeneidad y crear seguridad hacia adentro. Protegen el interior, generando espacios más pequeños, controlables y confiables. Al crear territorios socialmente más homogéneos y ordenados, y al organizar la vida de los residentes a través de regulaciones extremadamente meticulosas, la urbanización cerrada reduce la exposición de los sujetos a la alteridad y lo imprevisto. "Blinda" el territorio, reduciendo el espacio público, como lo describe Villarreal (2015) para el caso del municipio con alto poder adquisitivo de San Pedro Garza García en Monterrey. Este blindaje provoca que los sujetos se sienten más seguros adentro de las urbanizaciones cerradas y en sus inmediaciones, controladas por agentes privados y por la policía pública en cooperación con las asociaciones de colonos. ${ }^{2}$ En muchos casos asocian el exterior, fuera de los sectores de urbanizaciones cerradas, con el peligro y el temor (Capron

2 En los casos estudiados en Santa Fe y en Zona Esmeralda (al menos en 2010), la prestación del servicio de seguridad en las vialidades públicas que rodean las urbanizaciones cerradas, y también a veces dentro de ellas, era objeto de un contrato entre las federaciones de asociaciones de colonos y el gobierno municipal (Capron, 2019b). El vigilantismo que impera en gran parte de las Américas, en California (Davis \& Acker Chacón, 2009), pero también en países como Colombia y Brasil, no sirve, al menos en los casos que estudié, para interpretar la manera en que se da el servicio de seguridad. 
\& Alvizar, 2019). Como lo muestra Ceccato (2012) con un enfoque ecológico y situacional, las rutinas cotidianas de pasar las casetas, el ver a diario el entorno seguritario de las urbanizaciones cerradas, afectan el sentimiento de seguridad de los habitantes: "Se cree que los microespacios afectan el comportamiento espacial, las interacciones sociales y, finalmente, la geografía del crimen y del miedo" (p. 25).

En la concepción foucaultiana (Foucault, 2002), los dispositivos, aquí constituidos por leyes y normas (los reglamentos interiores del condominio), por elementos arquitectónicos (los muros, los accesos) y tecnologías de vigilancia (las cámaras), todos del orden privado, están inscritos en una relación de poder. Esta relación se construye en la base de desigualdades, no solo socioeconómicas sino simbólicas, entre los grupos; aquí, entre los residentes "ricos" y los trabajadores "pobres". Siguiendo a Lussault (2007), podemos sostener que el espacio también se vuelve dispositivo. El dispositivo espacial es un conjunto de actores humanos (los agentes de seguridad privados, la policía pública, la asociación de colonos) y actantes no humanos (los muros, las rejas, el arsenal tecnológico, los accesos en número reducido, no más de dos o tres en las grandes urbanizaciones cerradas) que actúan como operadores espaciales de las interacciones y las relaciones. El dispositivo espacial de la urbanización cerrada crea distancias y estructura un orden social desigual.

Los mecanismos de control y coerción que utilizan la forma material del encierro y del espacio-filtro ${ }^{3}$ como operadores de la segurización, proporcionan confianza social hacia los otros residentes al interior de sus condominios. La urbanización cerrada disminuye los riesgos, pero, como lo vimos, no elimina la sospecha social, eleva muros simbólicos.

Para limitar los riesgos asociados a la presencia de los intrusos tolerados, pero necesarios al buen funcionamiento de los conjuntos cerrados, se crean procedimientos, reglas y rituales del orden privado que buscan crear ciertas garantías. A diferencia de los aeropuertos, donde todos son iguales frente a la sospecha, en las urbanizaciones cerradas esta recae en los trabajadores. Las urbanizaciones cerradas clasifican a las personas según su grado de confiabilidad social y el riesgo que representan, las seleccionan y separan, les imponen reglas diferenciadas, acentuando las desigualdades simbólicas entre los grupos (Capron, 2019a). Los dispositivos privados expresan una fuerte desconfianza social hacia los trabajadores. Si bien los empleadores responden de aquellas empleadas domésticas en quienes depositan su confianza personal sobre la base de cartas de recomendación, deben solicitar una credencial para que sus trabajadoras -a las cuales incluso en ocasiones se les toman las huellas digitales- puedan entrar y salir de la urbanización. Los albañiles son controlados diariamente y necesitan una autorización temporal para ingresar a su trabajo. En muchas urbanizaciones cerradas, en particular en las más extensas, existe un acceso (o un ascensor en las torres de departamentos) para empleados y proveedores, donde es frecuente verlos hacer fila en los horarios de entrada y salida del trabajo; un segundo acceso para visitantes (familiares, amigos, etc.) y colonos o copropietarios atrasados con el pago de sus cuotas y molestos por el hecho de

3 Los accesos donde el filtro es operado por diferentes compañías privadas de seguridad y, a veces, la policía pública. 
que los discriminen, pero no molestos de que discrimen a sus trabajadores; y un tercer acceso para residentes con credencial o calcomanía, mucho más fluido. La separación de los accesos ya existía en los edificios en condominio con elevadores reservados a la servidumbre y otros para los residentes y las visitas, por ejemplo, en Río de Janeiro (Caldeira, 2000).

En las urbanizaciones cerradas, la separación y la clasificación entre entrantes se hace gracias a una parafernalia tecnológica propia de la ciudad vigilante. Lo más común es la existencia de cámaras de seguridad de tipo circuito cerrado de televisión (CCTV), pero a veces cuentan con tecnologías de punta, como el reconocimiento facial. Los vigilantes pueden tener a su disposición escáneres o sistemas biométricos sanguíneos de flujo de palma de mano. Incluso, en el caso de Condado de Sayavedra en Zona Esmeralda, se encuentra un centro de comando, comunicaciones y cómputo, C4, un dispositivo que utilizan los municipios para controlar su territorio (El Universal, 21/05/2018). Las tecnologías de videovigilancia están lejos de ser neutras. Como lo muestra Arteaga (2010, 2018), los operadores de las cámaras, frente a la cantidad de imágenes que visionan, tienen que enfocar su atención en ciertos elementos, en particular la manera en que está vestida la gente o en los comportamientos considerados anormales. De esta manera, los CCTV también contribuyen en construir al sospechoso. Por otro lado, en las salidas, las empleadas domésticas son sometidas a una revisión de sus pertenencias y hasta, a veces, a una revisión corporal, técnica de disciplinamiento y ejercicio de poder -del agente, de la institución- sobre las personas. Si salen con un objeto regalado por sus empleadores, el patrón debe notificar por escrito que le ha sido obsequiado. Estas revisiones son una violencia más de todas las que están viviendo los pobres en sus espacios de residencia (Auyero \& Berti, 2013), lejos de la tranquilidad de las urbanizaciones cerradas. Ellas, las empleadas, se sienten molestas, pero, a su vez, lo entienden y dicen que harían lo mismo si fueran ricas. En algunas urbanizaciones se prohíbe que los empleados caminen: deben tomar los taxis o transportes colectivos internos.

Si las patronas pueden confiar en sus empleadas, no confían en absoluto en las empleadas domésticas de los otros residentes, a las que desconocen. Los empleadores adhieren a las prácticas de cacheo en los accesos y, si bien algunas residentes se dicen apenadas de que sus empleadas sean revisadas por la policía cuando entran y salen y reconocen que puede haber abusos, lo ven como una necesidad para disminuir el riesgo. En este sentido, existe una tensión entre la "necesidad" imprescindible de la seguridad como algo que se impone en tiempos altamente inseguros y como un derecho, por un lado, y los valores morales defendidos por los individuos, en particular el respeto y la defensa de los derechos humanos, por el otro. Por ejemplo, a pesar de ser crítico hacia estas prácticas de cacheo, Juan (Lomas de Bezares, Santa $\mathrm{Fe}$ ) reconoce que "las circunstancias del país y de la inseguridad lo han obligado" y se dice "bastante creyente en los sistemas de seguridad. Entre más filtros, mejor". Existe, entre los residentes, una fuerte legitimización de los dispositivos de seguridad que justifica la segregación dentro de la urbanización cerrada. En este sentido, la seguridad está colonializando las subjetividades de los individuos. Los individuos, tanto residentes como empleados, normalizan e internalizan en sus mentes y cuerpos el imperativo de la seguridad. Este último produce "subjetividades seguritizadas", y eso 
es parte de la productividad de los dispositivos de seguridad y vigilancia y del "estado de seguridad” en el cual se encuentran insertos los sujetos (Glück \& Low, 2017).

Sin embargo, entre los entrevistados he encontrado a algunos -aunque pocos-, que no viven atemorizados, son críticos de la urbanización cerrada y subrayan el distanciamiento social que implica el vivir en una de ellas. Alejandro (inquilino en Bosque Real, Interlomas) dice haber apreciado vivir en una urbanización cerrada por la "exclusividad de la zona", pero reconoce que "este tipo de cosas te alejan y desconectan de habilidades sociales, aísla a las personas por distintas razones". Asimismo, como lo reflexiona Bertha (Bosques de Santa Fe, Santa Fe), "toda esta seguridad, en lugar de tender puentes, crea más muros (...), te ponen un muro, antes todas las calles en México eran abiertas, ahora en todas hay plumas [rejas] (...). Nos ha hecho un poco indiferentes en ciertas cosas; entonces es sano, es bueno, porque te sientes tú protegido (...), pero no ayuda a tener un mejor sistema donde la convivencia es más fácil; tiende a separarnos como sociedades”.

El mercado que selecciona a los residentes según sus ingresos económicos, haciendo caso omiso de su reputación o condición (pueden ser narcos sin que nadie se dé cuenta); las asociaciones de colonos y condominios, cuyos directivos, elegidos, tienen el poder delegado de organizar la seguridad pública y de establecer los reglamentos dentro de la urbanización cerrada, son garantes de la confianza, pero principalmente entre vecinos. De una confianza "asegurada", limitada, fundada en la segregación y en la predictibilidad y probabilidad de que los hechos ocurran, y no en una confianza abierta a la incertidumbre y basada en la benevolencia y en valores comunes. "Las relaciones negociadas producen seguridad, cuando las relaciones recíprocas proporcionan confianza" (Watier, 2008, p. 116). La desconfianza hacia los trabajadores promovida por el sistema de la urbanización cerrada es una disposición social y cultural para distanciarlos. Sin embargo, también se elevan voces en contra de inquilinos, locatarios de departamentos Airbnb, en particular en torres de viviendas en Santa Fe, "colombianos" y "venezolanos" que también empiezan a ser acusados de ser ladrones, lo que muestra que las fronteras no son inmutables y se van reconfigurando. De todos modos, la confianza en el sistema se construye sobre la creencia en la eficiencia y probidad mayores del sector privado frente al sector público, que ha sido objeto de una desvalorización sistemática en las economías neoliberales.

\section{Conclusiones}

En el caso de las urbanizaciones cerradas, la dimensión simbólica de la segregación es un efecto perverso de su dimensión económica y política, operada por dispositivos sociales y espaciales de vigilancia. Entender la segregación en las escalas espaciales micro ayuda a situarse a nivel de los actores sociales individuales y a captar esta dimensión. Sin embargo, me alejo del enfoque del individualismo metodológico que ve en las prácticas individuales un operador de la segregación. Los individuos no son responsables de la segregación residencial. No son tanto las prácticas y decisiones de los actores sociales, no homogéneas -tal vez sí su agregación- las que fomentan la segregación, sino más bien el sistema social y espacial de la urbanización cerrada. Pudiéramos calificarla de institución de vigilancia privada en el mismo 
sentido en que Foucault (2002) hablaba de instituciones disciplinarias. Se caracteriza por la búsqueda de un determinado concepto de orden, tanto social como espacial, operado por un reglamento y dispositivos de vigilancia como el patrullaje de la policía, ella misma vigilada, o las cámaras que permiten que el espacio del condominio sea permanentemente un lugar bajo supervisión, un espacio cerrado, un sistema de castigos (multas, separación o exclusión de los malos pagadores). El miedo se institucionaliza en los dispositivos de vigilancia a los cuales adhieren casi todos los residentes a nombre del imperativo de la seguridad, incluso con disonancias morales.

Estos dispositivos segregan los individuos, en particular a los trabajadores que son pobres, según su nivel de peligrosidad potencial y desconfiabilidad. En esta concepción, la confianza es un cálculo racional de disminución de riesgos. Si bien las clases pudientes siempre han tratado de distanciarse de los pobres en la ciudad, y también a escala micro -en el barrio, en la calle o en la casa- estableciendo fronteras simbólicas cuando existía proximidad espacial, lo nuevo es que los dispositivos socioespaciales de vigilancia (reglamentos, muro, accesos, policía) consolidan la relación de poder asimétrica entre los residentes pudientes y los empleados, pobres. Construyen distancias y fronteras que no solo son materiales, sino simbólicas, y marcan desigualdades también simbólicas que socavan la confianza. Los muros y los espacios-filtros (los accesos), los controles operados por los guardias de seguridad, son un símbolo de una increíble violencia hacia las personas que se emplean dentro de las urbanizaciones cerradas.

$\mathrm{Al}$ menos a través de la situación del empleo y de la relación de servicio, las clases media-alta y alta coexisten con sus empleados, aun con estas murallas simbólicas elevadas por las urbanizaciones cerradas. Nos podemos preguntar qué pasará si un día, como parece que está ocurriendo en países del norte, los trabajadores que se emplean en el sector de los servicios a las personas sean remplazados por cajas electrónicas en los supermercados, aspiradoras inteligentes en el interior de las casas, dispositivos electrónicos de vigilancia en los accesos de las urbanizaciones cerradas. ¿Se incrementará aún más el temor a las clases "peligrosas", siendo los dos mundos no solo simbólicamente aislados sino también físicamente paralelos, sin que los dos grupos tengan la posibilidad de cruzarse y menos de conocerse? ¿ $\mathrm{O}$, en América Latina, seguirá siendo el personal doméstico un marcador de distinción para las clases media-alta y alta, a la vez necesitado y temido?

\section{Agradecimientos}

Este trabajo fue realizado bajo el auspicio del proyecto del Consejo Nacional de la Ciencia y la Tecnología: Ciencia Básica número 256241, "La privatización de la seguridad pública en el Valle de México. Retos políticos, socioculturales y territoriales". 


\section{Referencias bibliográficas}

Aliaga-Linares, L. \& Álvarez-Rivadulla, M. J. (2010). Segregación residencial en Bogotá a través del tiempo y diferentes escalas. Documento de trabajo de Lincoln Institute of Land Policy. https://bit.ly/3hbvi3u

Arteaga, N. (2010). Video-vigilancia del espacio urbano: tránsito, seguridad y control social. Andamios, 7(14), 263-286. https://andamios.uacm.edu.mx/index.php/andamios/ article/view/108

Arteaga, N. (2018). Videovigilancia en México: protesta política, conflicto y orden social. Ciudad de México: Flacso México.

Auyero, J. \& Berti, M. F. (2013). La violencia en los márgenes. Una maestra y un sociólogo en el conurbano bonaerense. Buenos Aires: Katz editores.

Bauman, Z. (2007). Miedo líquido. La sociedad contemporánea y sus temores. Madrid: Paidós, col. Estado y Sociedad.

Caldeira, T. (2000). Cidade de Muros: crime, segregaçao e cidadania em São Paulo. São Paulo: Edsup.

Capron, G. (2019a). Las desigualdades simbólicas en un sector de urbanizaciones cerradas en la Zona Metropolitana del Valle de México. En C. Bayón (Ed.), Las grietas del neoliberalismo. Dimensiones de la desigualdad contemporánea en México (pp. 357-382). Ciudad de México: unam.

Capron, G. (2019b). Coproducción de la seguridad pública en urbanizaciones cerradas del Valle de México. Nueva Antropología, 32(91), 10-25. https://bit.ly/322HQ6O

Capron, G. \& Esquivel, M. T. (2016). El enclave urbano, lógica socioespacial de la periferia urbanizada y sus efectos sobre la segregación residencial y la fragmentación urbana. Cuadernos de Geografía. Revista Colombiana, 25(2), 127-150. https://doi. org/10.15446/rcdg.v25n2.54720

Capron, G. \& Alvizar, O. (2019). Vivir tras los muros: malestar urbano, miedo e inseguridad en un sector de urbanizaciones cerradas. En M. Moreno \& G. Crysler (Eds.), Espacios de miedo: cuerpos, muros, ciudades (pp. 141-182). Ciudad de México: uAm Cuajimalpa.

Ceccato, V. (2012). The urban fabric of fear and crime. Dordrecht: Springer.

Chamboredon, J.-C. \& Lemaire, M. (1970). Proximité spatiale et distance sociale: les grands ensembles et leur peuplement. Revue Française de Sociologie, 11(1), 3-33. https://www. persee.fr/doc/rfsoc_0035-2969_1970_num_11_1_1610

Davis, M. (1990, 2003). Ciudad de Cuarzo. Arqueología del futuro de Los Ángeles. Madrid: Ediciones Lengua de Trapo.

Davis, M. \& Akers Chacón, J. (2009). Nadie es ilegal. Combatiendo el racismo y la violencia de Estado en la frontera Estados Unidos-México. Chicago, IL: Haymarkets Books.

Díaz, J. (2019). Le centre historique de Mexico. De la patrimonialisation du site à la gentrification. Toulouse: Presses universitaires du Midi.

Donzelot, J. (1999). La nouvelle question urbaine. Esprit, (11), 87-114. https://www.jstor.org/ stable/24278387?seq=1

Douglas, M. (1973). Pureza y peligro. Un análisis de los conceptos de contaminación y tabú. Madrid: Siglo xxi.

Dureau, F., Lulle, T., Souchaud, S. \& Contreras, Y. (2015). Movilidades y cambio urbano. Bogotá, Santiago y Sao Paulo. Bogotá: Universidad Externado de Colombia. 
Durin, S. (2013). Servicio doméstico de planta y discriminación en el área metropolitana de Monterrey. Relaciones. Estudios de historia y sociedad, 34(134), 93-129. http://www. revistarelaciones.com/index.php/relaciones/article/view/461

Foucault, M. (2002). Vigilar y castigar: nacimiento de la prisión. Buenos Aires: Siglo XXI.

Galeano Gasca, E. N. (2018). El don y la construcción de confianza por parte de jóvenes artistas en contextos de violencia física y estructural en Medellín, Colombia. Nueva Antropología, 30(87), 84-106. http://www.scielo.org.mx/scielo.php?script=sci_arttext \&pid=S0185-06362017000200084

Glück, Z. \& Low, S. (2017). A sociospatial framework for the anthropology of security. Anthropological Theory, 17(3), 281-296. https://journals.sagepub.com/doi/10.1177/ 1463499617729229

Grafmeyer, Y. (1994). Regards sociologiques sur la ségrégation. En J. Brun \& C. Rhein (Eds.), La ségrégation dans la ville (pp. 85-116). París: L’Harmattan.

Garrido, M. (2013). The sense of place behind segregating practices: An ethnographic approach to the symbolic partitioning of Metro Manila. Social Forces, 91(4), 1343-1362. https:// doi.org/10.1093/sf/sot039

Kessler, G. (2008). El sentimiento de inseguridad. Sociología del temor al delito. Buenos Aires: Siglo xxI.

Lacarrieu, M. \& Thuillier, G. (2004). Une utopie de l'ordre et de la fermeture: "quartiers privés" et "countries" à Buenos Aires. L'Espace géographique, 33(2), 149-164. https:// www.cairn.info/article.php?ID_ARTICLE=EG_332_0149

Lamont, M. \& Molnár, V. (2002). The study of boundaries in the social sciences. Annual Review of Sociology, 28, 167-195. https://doi.org/10.1146/annurev.soc.28.110601.141107

Low, S. (2003). Behind the gates. Life, security and the pursuit of happiness in the fortress America. Nueva York y Londres: Routledge.

Lunecke, A. (2016). Inseguridad ciudadana y diferenciación social en el nivel microbarrial: el caso del sector Santo Tomás, Santiago de Chile. EURE, 42(125), 109-129. http:// dx.doi.org/10.4067/S0250-71612016000100005

Lussault, M. (2007). L'homme spatial. La construction sociale de l'espace humain. París: Seuil.

Massey, D. \& Denton, N. (1988). The dimensions of residential Segregation. Social Forces, 67(2), 281-315. https://www.jstor.org/stable/2579183?seq=1

Moctezuma, V. (2017). Experiencia y significados simbólicos de los habitantes de conjuntos urbanos de interés social en México: segregación, diferenciación y distinción. Estudios Demográficos y Urbanos, 32(3), 487-514. https://estudiosdemograficosyurbanos. colmex.mx/index.php/edu/article/view/1723

Pérez, F. (2013). La consolidación de la segregación espacial desde las prácticas e imaginarios cotidianos de la vida doméstica 1930-1960. En M. Carman, N. Vieira da Cunha \& R. Segura (Eds.), Segregación y diferencia en la ciudad (pp. 197-224). Quito: FlacsoClacso-Miduvi.

Pérez, M. (2011). The emergence of gated communities in the poor periphery: Reflections on the new urban segregation and social integration in Santiago, Chile. Berkeley Planning Journal, 24(1), 1-13. https://doi.org/10.5070/BP324111861

Piccato, P. (2010). Ciudad de sospechosos. Crimen en la Ciudad de México 1900-1931. Ciudad de México: Ciesas. 
Rodríguez, M. G. (2014). Qué es y no es segregación residencial. Contribuciones para un debate pendiente. Biblio 3W, XIX(1079), s.p. http://www:ub:edu/geocrit/b3w-1079. htm

Roitman, S. (2003). Barrios cerrados y segregación social urbana. Scripta Nova, VII(146), s.p. http://www.ub.edu/geocrit/sn/sn-146(118).htm

Ruiz-Tagle, J. (2016). La persistencia de la segregación y la desigualdad en barrios socialmente diversos: un estudio de caso en La Florida, Santiago. EURE, 42(125), 81-108. https:// eure.cl/index.php/eure/article/view/1330

Ruiz-Tagle, J. \& López, E. (2014). El estudio de la segregación residencial en Santiago de Chile: revisión crítica de algunos problemas metodológicos y conceptuales. EURE, 4O(119), 25-48. https://eure.cl/index.php/eure/article/view/393

Sabatini, F. (2003). La segregación social del espacio en las ciudades de América Latina. Santiago: Pontificia Universidad Católica de Chile, Documentos del Instituto de Estudios Urbanos y Territoriales, Serie Azul n 35.

Sabatini, F. \& Brain, I. (2008). La segregación, los guetos y la integración urbana: mitos y claves. EURE, 34(103), 5-26. https://www.eure.cl/index.php/eure/article/view/1361

Sabatini, F., Cáceres, G. \& Cerda, J. (2001). Segregación residencial en las principales ciudades chilenas: Tendencias de las tres últimas décadas y posibles cursos de acción. EURE, 27(82), 21-42. https://www.eure.cl/index.php/eure/article/view/1258

Sabatini, F., Rasse, A., Mora, P. \& Brain, I. (2012). ¿Es posible la integración residencial en las ciudades chilenas? Disposición de los grupos medios y altos a la integración con grupos de extracción popular. EURE, 38(115), 159-194. https://eure.cl/index.php/ eure/article/view/252

Sabatini, F. \& Salcedo, R. (2007). Gated communities and the poor in Santiago, Chile: Functional and symbolic integration in a context of aggressive capitalist colonization of lower-class areas. Housing Policy Debate, 18(3), 577-606. https://doi.org/10.1080/ 10511482.2007.9521612

Saraví, G. (2008). Mundos aislados: segregación urbana y desigualdad en la ciudad de México. EURE, 34(103), 93-110. https://scielo.conicyt.cl/scielo.php?script=sci_arttext\&pid $=$ S0250-71612008000300005

Swyngedouw, E. (2013). The segregation of social interactions in the Red Line L-Train in Chicago. Symbolic Interaction, 36(3), 293-313. https://doi.org/10.1002/symb.64

Toledo, M. (2013). El papel de la confianza en los arreglos particulares del trabajo doméstico remunerado. Trayectorias, 15(36), 45-64. https://dialnet.unirioja.es/servlet/ articulo?codigo $=7369775$

Vidal, D. (2007). Les bonnes de Rio. Emploi domestique et société démocratique au Brésil. Villeneuve d'Asq: Presses Universitaires du Septentrion.

Villarreal, A. (2015). Fear and spectacular drug violence in Monterrey. En J. Auyero, P. Bourgois \& N. Scheper-Hughes (Eds.), Violence at the urban margins (Chapter 6). Oxford University Press. https://doi.org/10.1093/acprof:oso/9780190221447.003.0007

Watier, P. (2008). Éloge de la confiance. Aux sources de la socialité. París: Belin. 